\title{
Application of “Trinity" Experiential Teaching in Innovation and Entrepreneurship Education in Chinese Universities
}

\author{
Lijuan Yan*, Yin Qiang \\ School of Economics and Management, Heilongjiang Bayi Agricultural University, Daqing, 163319, \\ Heilongjiang, China
}

Keywords: experiential teaching; innovation and entrepreneurship education; innovation and entrepreneurship talents

Abstract: In the final analysis, the competition for national power in the world is competition for talents. If China wants to be invincible in international competition, it must cultivate more creative and entrepreneurial talents to fill the gap of social complex talents and provide new and inexhaustible motive forces for social and economic development. In this respect, the Ministry of Education called on innovation and entrepreneurship education to enter college classrooms. But how to make innovation and entrepreneurship education truly cultivate qualified innovation and entrepreneurship talents becomes the top priority. At present, how to carry out innovation and entrepreneurship education in China is more effective, the "experiential teaching method" is particularly noticeable among many reference answers. This article takes "experiential teaching" as the starting point, tries to integrate it into innovation and entrepreneurship education, and solves the main problems faced by China in developing innovation and entrepreneurship education. It also puts forward a talent training and transportation chain with the "Trinity" as its main idea, hoping to put forward useful suggestions for the innovation and entrepreneurship education of Chinese universities.

\section{The Significance of Experiential Teaching to Innovation and Entrepreneurship Education in China}

At present, China's economic development is progressing steadily, and the transformation and upgrading of the industrial structure is at a critical point in time. The demand for innovative and entrepreneurial talents has increased unprecedentedly. In order to respond to the national call and the needs of social transformation and upgrading, the Ministry of Education has issued regulations to include innovation and entrepreneurship education in the compulsory courses of colleges and universities. Nowadays, foreign innovation and entrepreneurship education started earlier and has become a source of domestic reference. However, the "bringing-in" approach is not advisable. Direct grafting is often separated from the soil of innovation and entrepreneurship education in China. The research of innovation and entrepreneurship education in foreign countries has lasted for quite a long time. Students have established a double-creation ideology since childhood. The 
atmosphere created by society and the provided assistance system are relatively mature. However, China's innovation and entrepreneurship education has only been carried out for more than ten years. In the junior high school education stage, there is a lack of continuous and coherent knowledge of innovation and entrepreneurship. And the atmosphere of the environment of innovation and entrepreneurship has been in a state of scarcity in society. Therefore, based on China's national conditions, a rational comparison of innovation and entrepreneurship education models at home and abroad, drawing on advanced foreign experience, and creatively exploring innovative entrepreneurship education models suitable for Chinese universities is the top priority.

Based on China's current development stage of innovation and entrepreneurship education, the introduction of experiential teaching is more in line with China's national conditions. Experiential teaching is based on the students' cognitive ability, which enables students to understand the content in the process of personal experience, to independently build systems and values, to cultivate comprehensive qualities and abilities, to generate perceptions, and to generate meanings of teaching concepts and teaching forms. Experiential teaching advocates a high degree of interaction and pays attention to the real feelings of both teachers and students in the teaching process. It has the following characteristics [1]. First of all, experiential teaching respects the uniqueness of life. In the course of teaching, we must ensure that students are fully guided into the context of the curriculum. There are not too many rules, but only the goals to be achieved. As for the process of how to achieve the goal, students should explore it by themselves, fully showing the individuality of each person and respecting the uniqueness of each individual's life. Let students break through the situation, achieve the goal and unlock the sense of achievement with the strength of individual or collective. Secondly, experiential teaching treats the autonomy of life kindly. How to let students learn and acquire knowledge independently is the focus of experiential teaching exploration. With autonomy, students have a constant flow of motivation and passion that passive learning does not have, which can make students enjoy themselves and teach with pleasure. In the process of solving situational problems, simulation experiments, find ways to solve problems, test you attitude towards problems, and even find out the direction of future efforts. Thirdly, experiential teaching understands the generative nature of life. Nowadays, most of the education is result-oriented theory, which is based on achievement theory, rather than focusing on the process of education. Experiential teaching guides students to fully experience the process, understand the problems that may be encountered in real life, and through the process of analyzing problems, formulating countermeasures, solving problems and generating perceptions, let students get real growth. Finally, experiential teaching cares about the integrity of life. In daily learning and life, students often only want to show the good side. But in real life, failure is often due to its own weaknesses and problems. Life is holistic and no one can be perfect, so it is not a bad thing to expose problems and weaknesses. Finding problems in time and solving them in school will be of great benefit to the actual development of students in the future. Teachers position students as the main body of the classroom. As long as students show a positive response, whether the result is good or bad, it is the performance of life integrity, and it is worth encouraging and guiding.

In a word, this form of education matches the objective needs of innovation and entrepreneurship education well. Carrying out innovation and entrepreneurship education with experiential teaching can enable students who are new to innovation and entrepreneurship education to quickly integrate into the classroom, truly and effectively explore their potential talents, and gain real knowledge and insights. 


\section{The Comparison Between Chinese and Foreign Innovation and Entrepreneurship Education and the Necessity of Implementing Experiential Education Model}

\subsection{Popularization of Innovation and Entrepreneurship Education in Junior and Secondary Education}

In the field of innovation and entrepreneurship education, the research of foreign developed countries in related fields has lasted for decades or even nearly a century, and a complete and mature system has been established, covering formal education from elementary school, junior high school, senior high school, college to undergraduate and graduate. It is understood that the British government has started business courses from middle schools and requires all middle school students aged 12 to 18 to participate in a two-week business training [2]. Since 1998, the United States has implemented the "Financial Literacy 2001 Plan" to popularize "advanced education" in finance, investment, financial management, marketing, business and other aspects to middle school students [3]. Japan has implemented employment and entrepreneurship education since primary school, carried out workplace experience activities and visited the workplace [4]. At the middle school level, there is teaching content for workplace internships. However, the innovation and entrepreneurship education in China is still in the stage of fragmentation and short-term. Innovation and entrepreneurship education has only been implemented for more than ten years, and more education resources are invested in higher education. Before the University, there was very little education in this field from primary school to high school. The foundation for Chinese students to receive relevant knowledge before college is very weak, and children in more developed countries have significant gaps in their knowledge and understanding of innovation and entrepreneurship. Foreign education systems and models may be suitable for China, but all references should be based on the actual national conditions of Chinese students and education systems, and the parts suitable for education audiences should be introduced, updated and improved.

\subsection{Comparison of Implementation Status of Innovation and Entrepreneurship Education in Higher Education}

At the higher education level, the maturity gap in the field of innovation and entrepreneurship education at home and abroad has become increasingly apparent. The developed countries of the world have completed the elementary and secondary innovation and entrepreneurship education, and the elements of the innovation and entrepreneurship curriculum system in the higher education stage are very complete, forming a relatively mature talent training chain. However, China's innovation and entrepreneurship education has really begun in the higher education stage, and there are great differences between domestic and foreign innovation and entrepreneurship education in this stage.

\subsubsection{Course Setting}

Foreign colleges and universities have reserved theoretical knowledge of innovation and entrepreneurship for students before entering colleges and universities, so the courses in higher education stage focus on the purpose of practice. The courses are mainly arranged for a long period of time, allowing students to choose topics, explore and practice independently, and form unique experiences and perceptions [5]. In contrast, in the light of the above, due to the lack of innovation and entrepreneurship education in the elementary and secondary education stages, basic courses and theories have only just begun at the university stage, and there are few practical teaching platforms, which cannot provide students with sufficient simulation teaching and practice opportunities. For 
most students, what can be learned in a limited course of innovation and entrepreneurship is only the awareness of innovation, but it is difficult to master the practical skills of innovation and entrepreneurship.

\subsubsection{Teaching Mode}

Innovative and entrepreneurial courses in foreign universities have generally formed a form of teaching based on students. Teachers only need to act as course guides, rule makers and discipline maintainers in the classroom. In the classroom, students accept simulated practice tasks posted by the teacher, start preliminary thinking, set up groups, and analyze problems. Finally, the ideas are summarized to form a relatively complete solution, and tasks are reported in a group form, or the goals of innovation and entrepreneurship are directly established, and an innovation and entrepreneurship team is formed to carry out the actual operation. The above model fully aroused students' participation. The opportunity to build a theoretical kingdom for students from the perspective of constructivism is currently the most suitable teaching mode for innovation and entrepreneurship education [6,7]. Most of China's innovation and entrepreneurship classrooms still use the traditional model, with teachers as the center, single direction theory output, low interaction between teachers and students, and weak student participation. There is no distinction between innovation and entrepreneurship education and traditional theoretical education.

\subsubsection{Structure of Teachers}

Foreign colleges and universities mostly adopt the combination of theoretical and practical teachers to teach. In addition to hiring full-time teachers with many years of experience in innovation and entrepreneurship, they also look for successful entrepreneurs and talents in the field of innovation and entrepreneurship to enter campus as part-time teachers. Bring the latest elements of innovation and entrepreneurship and real personal lessons to students in school in real time. This teacher structure has greatly helped students on campus to carry out innovation and entrepreneurship in the future. However, most of the teachers of innovation and entrepreneurship education in our country are the teachers of relevant specialties after the compulsory courses are set up by the state, and there is a lack of practical teachers [8].

\subsubsection{Practice Platform}

Foreign universities generally carry out cooperation projects with social enterprises. The enterprise provides the school with funds, technology and practical platform [9]. The school brings new blood and new plastics to the company. Under the cooperation of schools and enterprises, students have gained vital interests. After receiving innovation and entrepreneurship education on campus, students apply to practice on the enterprise platform, and they are familiar with the details of the innovation and entrepreneurship process in advance. If you have a high-value idea, you will even get direct support from all aspects of the business. Everything has laid a solid foundation for students' future innovation and entrepreneurship actions. Most of the off campus practice of college students in China are confined to professional internships once every four years. In addition, there are few practical opportunities offered by schools. Participation of enterprises in the higher education stage is not strong. Most of the school-enterprise cooperation mainly focuses on improving professional skills, and there are very few platforms for enhancing innovation awareness and providing entrepreneurial space [10]. Students' innovation and entrepreneurial ability stays on campus, and does not really meet the needs of society.

Through the above comparative research, the problems that China's innovation and entrepreneurship urgently need to solve are summarized as follows. (1) Emphasize the subject 
identity of students in innovation and entrepreneurship education. Clarify the purpose of curriculum setting, point out the differences between innovation and entrepreneurship courses and other theoretical courses, and establish the necessity of students' subject status in innovation and entrepreneurship education. (2) Correct guidance of colleges and universities in innovation and entrepreneurship education. Innovation and entrepreneurship education has its particularity and importance at present, which requires colleges and universities to play an important guiding role. The establishment of the innovation and entrepreneurship education department, the construction of the teaching staff, the setting of the curriculum, and the construction of the practice platform within the university are inseparable from the correct traction of the university. (3) Give full play to the role of social organizations in innovation and entrepreneurship education. It is difficult to solve the problem of lack of practice platform only by the strength of colleges and universities, which requires the participation and assistance of social organizations to jointly realize the cultivation of innovative and entrepreneurial talents. Both the guidance of colleges and the help of social organizations are inseparable from the students' own efforts and practices. Therefore, the experiential teaching model can better guarantee the achievement of the goals of innovation and entrepreneurship education.

\section{Create a "Trinity" Innovation and Entrepreneurship Talent Transportation Chain Based on Experiential Teaching}

Innovation and entrepreneurship education should not only offer relevant courses in schools for theoretical learning, but also be tested in social places outside schools. The innovation and entrepreneurial knowledge and theories that students get in the classroom need to be socially practiced in order to truly "learn what they have learned." Therefore, based on the experiential teaching model, we will create a creative, entrepreneurial and talented person transportation chain in which the "Trinity" of students, universities and society participates together.

\subsection{Application of Experiential Teaching in Innovative Entrepreneurship Education Drives Students to Sail}

The first and most important part of innovation and entrepreneurship education is the self-discovery of students, that is, students discover and explore ideas for innovation and entrepreneurship by themselves, and can seize the fleeting "golden ideas". As a subversive teaching mode, experiential teaching makes students become the center of the classroom [11]. The progress and depth of the course are explored by students under the guidance of teachers. Guided by the teacher, the students generate their own unique lessons. Through rich simulated teaching or training activities in the classroom, establish a systematic knowledge system and correct values. Avoiding students 'resistance to innovation and entrepreneurship due to boring courses, fundamentally correcting college students' perceptions of dual innovation, allowing students to confidently imagine the future

and move into the realm of innovation and entrepreneurship with proven theory and experience [12].

\subsection{Colleges Pilot Experiential Teaching for Innovation and Entrepreneurship}

If we want to give play to the important role of schools in the cultivation of innovative and entrepreneurial talents, we must break the boundaries of ideas and concepts. Let innovation and entrepreneurship education out of the classroom, extend to society, lead by the actual needs of society and trends. Establish a sound innovation and entrepreneurship education system and a complete support system, allow social organizations and business enterprises to participate in, and 
start "school-enterprise cooperation." Adopting "school-enterprise cooperation" as the second classroom for students' creative education, providing students with extra-curricular practice positions, allowing students to get in touch with the real world in advance, accumulate valuable experiences and useful lessons, and lay a solid foundation for truly launching innovation and entrepreneurship in the future. Finally, connect the students' transition from school to society. Transfer mature, novel, and operational projects in the school to relevant institutions, and allow relevant departments to support these projects, help dreaming young entrepreneurs to complete the relay of imagination and reality, and let the achievements of innovation and entrepreneurship education truly come to the benefit of society, Serve the country.

\subsection{Society Becomes a Testing Ground for Experiential Teaching in Innovation and Entrepreneurship Education}

The last link is social support management. The current social environment has created a good atmosphere for innovation and entrepreneurship, and relevant departments have carried out effective publicity and support. The state has continuously issued innovation and entrepreneurship policies, which has provided more preparations for college graduates with ideas on innovation and entrepreneurship. After self-study and school training, students with the experience developed in experiential teaching and understanding of national innovation and entrepreneurship policies and service agencies, go to society with enthusiasm and wisdom, trying to complete the initial cultivation of innovation and entrepreneurship through the large stage of society Success and incubation, at this time society has become a testing ground for testing student learning results and school teaching achievements. This proving ground has ample opportunities provided by society, but also risks and challenges. It requires the help of all parties in the society to help, tolerate and encourage them to successfully pass the incubation period and to mature.

\section{Summary}

The innovation and entrepreneurial talent transportation chain consisting of students, universities, and society based on the experiential teaching model can become a "medical cure" for slow and inefficient repetition of China's universities' innovation and entrepreneurship education. Students who have gone through the "Trinity" innovation and entrepreneurship training system can better understand the internal and external environment and analyze the actual situation than others. Seize the opportunity, avoid the risks, and become the new type of talents who want to create two, create a school, and dare to create two. Such talents meet the needs of society and country and can provide a steady stream of power for national modernization.

\section{Acknowledgements}

This research is financially supported by the: Heilongjiang Bayi Agricultural University 'Three horizontal and three vertical 'Project "Participatory Projects' Research on Management Mode of training programs for innovation and entrepreneurshipin University（No. RRCPY201803）.

\section{References}

[1] Wang Jing. Exploration of experiential teaching in innovation and entrepreneurship education curriculum. Journal of Shaoguan University, 2014, 35 (04): 109-112.

[2] Singh, H., Tulsi, P.K., Dutt, S., Dalvi, G. The effect of contextual teaching learning of microprocessors on the achievement of degree level students. Engineering Education: Innovative Practices and Future Trends (AICERA), 2012 IEEE International Conference on, 2012. 
[3] Inna Kozlinska. Contemporary Approaches to Entrepreneurship Education. Journal of Business Management, 2011, (4):157-164

[4] Min TANG, Cai-xia LIAO, Jun LIU, Yong-cheng ZHOU. Research on Curriculum System of Innovation and Entrepreneurship Education in Higher Vocational Colleges-About Training Mode of Comprehensive Talents. International Conference on Modern Education and Information Technology (MEIT 2017), 2017.

[5] Fouad N A, Ghosh A, Chang W, et al. Career Exploration among College Students. Journal of College Student Development, 2016, 57(4):460-464.

[6] Colin Mason, Norin Arshed. Teaching Entrepreneurship to University Students Through Experiential Learning. Industry and Higher Education. 2013, 449-463.

[7] Cheng Hua, Yuan Zhi zhong. Application of experiential teaching method in teaching practice. China Electric Power Education, 2012 (1): 24-25.

[8] Ding Xiaolan. Experiential teaching method and its application in teaching Journal of Zhejiang Shuren University, 2012 (3): 78-80

[9] Zhang Yuguang, Diao Yanbin. Exploring the Experiential Innovation and Entrepreneurship Education Model in Colleges and Universities. China Higher Education, 2017 (06): 61-63.

[10] Sui Shanshan, Qian Fenghuan, Wang Shuen. An Analysis of the Path of Cultivating Innovation and Entrepreneurship Talents in China_Based on the Comparison of Foreign Experiences and the Construction of Innovation and Entrepreneurship Education Ecosystem .Research of Scientific Management, 2018, 36 (05): 105-108.

[11] Ju Meishan, Pu Xuetao. On the Educational Culture of Innovation and Entrepreneurship in Colleges and Universities. Science Teaching Journal (mid-term), 2019 (01): 175-176.

[12] Wang Bin. Development and Problems of College Students' Innovation and Entrepreneurship Education. China Collective Economy, 2019 (04): 158-159. 